\title{
Una aproximación a la Esperanza en Joseph Ratzinger
}

\author{
An Approach to Hope in Joseph Ratzinger
}

\author{
Miguel Ángel Núñez Aguilera \\ Facultad de Teología San Isidoro de Sevilla \\ xtospes@gmail.com
}

\begin{abstract}
Resumen: Si bien la obra de Joseph Ratzinger es rica en interpolaciones sobre la esperanza, carece sin embargo de una presentación sistemática. La presente investigación, recogi ndo todo el corpus ratzingeriano, pretende ofrecer una sistematización del tema e esperanza, su fundamento bíblico, su estructura antropológica y su composición teológica.
\end{abstract}

Palabras clave: Ratzinger, esperanza

\begin{abstract}
While Joseph Ratzinger's work is rich in insights about hope, it nevertheless lacks a systematic presentation. The present investigation, gathering all the ratzingerian corpus, intends to offer a systematization of the theme of hope, its biblical foundation, its anthropological structure and its theological composition.
\end{abstract}

Keywords: Ratzinger, hope

Tras la publicación en 1977 del libro Escatología, ${ }^{1}$ Joseph Ratzinger dedicó un sustancioso artículo a la esperanza en 1984, titulado precisamente "Sobre la esperanza". ${ }^{2}$ Este recoge su intervención en las conferencias que, con motivo del 50 aniversario del Antonianum, se organizaron el año anterior en Roma bajo el lema"Francisco, testigo y guardián de la esperanza". Pese al subrayado franciscano de su reflexión, nuestro autor se extiende en esta pieza más allá del franciscanismo para abordar la cuestión de la esperanza tanto en su aspecto antropológico como en el teológico. Dentro de este horizonte mayor, dos años después, Ratzinger dirige ejercicios espirituales en torno a las virtudes teologales, dedicando buena parte de ellos a la esperanza. Aquellas palabras pueden leerse hoy en su libro Mirar a Cristo. ${ }^{3}$

1 Si bien se trata de una obra monográfica sobre los novísimos, según Ratzinger mismo recoge allí:"En la temática escatológica entra, sin duda, la cuestión del futuro y el presente y con ella todo lo referente a la esperanza y su práctica": Joseph RATZINGER, Escatología. La muerte y la vida eterna, 1977, en IDEM, Obras Completas, vol. X, Madrid, BAC, 2017, 13.

2 Cf. Joseph Ratzinger, "Sobre la esperanza", 1984, en IDEm, Obras Completas, vol. X, Madrid, BAC, 2017, 390-406.

3 Cf. Joseph Ratzinger, Mirar a Cristo, 1989, Valencia, EDICEP, 2005. 
Además de los textos referidos, el corpus ratzingeriano es rico en interpolaciones sobre la esperanza. Estas pueden agruparse, de modo sumario, en dos líneas de reflexión: la razón cristiana para la esperanza, singularmente ante la muerte, ${ }^{4} \mathrm{y}$ las formas temporales de la esperanza, la memoria cuando mira al pasado y la profecía respecto al futuro. Tal es el caso de "Una memoria que suscita esperanza", texto de 1981, donde a propósito del Adviento, traza la relación entre esperanza y memoria, o de su entrevista "El problema de la profecía cristiana", de 1994, donde la esperanza es ingrediente del futuro. ${ }^{5}$

El bagaje reflexivo que ofrecen estos textos, en su diversidad de enfoques y géneros, bien puede considerarse la base de la segunda de las encíclicas de Benedicto XVI: Spe Salvi. En ella, salvando la distinción que se impone entre la reflexión de un teólogo y la enseñanza magisterial a la que se debe un pontífice, sus apuntes sobre la esperanza encuentran de algún modo sistematización. Precisamente esta elemental distinción que ha de hacerse entre los escritos del teólogo Ratzinger y el magisterio de Benedicto XVI, delimita consigo nuestra investigación. El estudio que hoy presentamos sobre la esperanza se ciñe exclusivamente a la obra teológica ratzingeriana, dejando para otro momento el magisterio de Benedicto XVI al respecto, así como el análisis cruzado de ambos materiales.

En el cuerpo temático que constituyen los artículos ya referidos, nuestro teólogo se pregunta tanto por el desencanto de los jóvenes ${ }^{6}$ como por $^{-}$ la desesperanza en la que se hunden los mayores. ${ }^{7}$ Con tono autocrítico, Ratzinger no deja de interpelarse por la responsabilidad del cristianismo en ello: " ¿no es verdad que, por lo general, los cristianos han ofrecido una imagen que estaba más marcada por el temor que por la esperanza?". Ítem más, abundando en los motivos de esta pérdida de esperanza, a propósito del paradigma materialista e intramundano actual, se cuestiona si

4 Además de la ya mencionada obra Escatología, sobre este aspecto destacan: Joseph RAtZinger, "La resurrección de Cristo y la esperanza cristiana en el más allá", 1972, en IDEM, Obras Completas, vol. X, Madrid, BAC, 2017, 346-348; IDEM, "Lugares de esperanza: Las catacumbas romanas", 1986, en IDEM, Obras Completas, vol. X, Madrid, BAC, 2017, 645-649; IDEM, ¿Qué tengo que hacer para heredar la vida? Lc 10,25-37", 1988, en IDEM, Mirar a Cristo, Valencia, EDICEP, 2005, 113-118; IDEM, "Mi felicidad es estar cerca de ti", 1992, en IDEM, Obras Completas, vol. X, Madrid, BAC, 2017, 430-446.

5 Cf. Joseph RATZINGER, "Una memoria que suscita esperanza", 1981, en IDEM, El resplandor de Dios en nuestro tiempo, Barcelona, Herder, 2008, 19-22; IDEM, "Esperanza cumplida", 1990, en IDEM, Obras Completas, vol. X, Madrid, BAC, 2017, 650-652; IDEM, "El problema de la profecía cristiana", 1994, en IDEM, Obras Completas, vol. X, Madrid, BAC, 2017, 448-464.

6 Cf. Ratzinger, “Una memoria que suscita esperanza”, 21; IDEM, Mirar a Cristo, 74-77.

7 Cf. RATZINGER,"Esperanza cumplida”, 651.

8 RATZINGER, “Sobre la esperanza”, 390. 
la entrega de la vida a la pura satisfacción material ha podido acabar con la esperanza que reclama el anhelo más profundo del hombre, ${ }^{9}$ así como si la esperanza ofrecida por el cristianismo "¿no era demasiado pequeña, ajustada en exceso a la medida del propio yo?". ${ }^{10}$ De donde se inquiere: " ¿No estamos acaso en peligro de que los sinsabores cotidianos nos hagan perder la gracia de la esperanza?". ${ }^{11}$ Si fuese así, "¿cómo podría uno vivir sin esperanza y sin el menor cumplimiento feliz?", ${ }^{12}$ y, en consecuencia, la vida humana “ ¿es absurda, desesperación, vía inútil hacia la muerte?". ${ }^{13}$

Al final de este conjunto de interrogantes a través de los cuales analiza la situación actual de la esperanza, nuestro teólogo tematiza la cuestión en tres núcleos esenciales: ¿Qué es realmente la esperanza?, ¿quién espera? y ¿qué esperan los que esperan ${ }^{14}$

\section{FUENTES BÍBLICAS DE LA REFLEXIÓN RATZINGERIANA SOBRE LA ESPERANZA}

En su reflexión sobre la esperanza, Joseph Ratzinger se remite a una pléyade de textos neotestamentarios, sobre todo paulinos; aunque no solo.

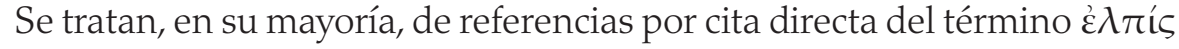
(esperanza). Para la exégesis, nuestro autor se apoya en los estudios de Heinrich Schlier, a quien admira y con quien compartió un singular proyecto de formación teológica para jóvenes entre 1970 y 1977,15 Helmut Koester, Karl Rensgtorf, Ernst Käsemann y Hartmut Gese. ${ }^{16}$

Del corpus paulino, Ratzinger cita la Carta a los Efesios en tres puntos: Ef 1,18, donde Pablo implora de Dios la luz para los corazones de los efesios a fin de que entiendan cuál es la esperanza a la que han sido llamados; Ef 2,12, donde recuerda a sus lectores el tiempo en que no eran cristianos y vivían ajenos a la promesa, sin Dios y sin esperanza;

\footnotetext{
9 “¿Le faltará, en medio de la superabundancia, el recuerdo de lo humanamente bueno que podría esperarse?": RATZINGER, “Una memoria que suscita esperanza”, 21.

10 RatZingeR, “Esperanza cumplida”, 651.

11 RATZinger, "Sobre la esperanza", 401.

12 RATZINGER, "Esperanza cumplida”, 651.

13 Ratzinger, Mirar a Cristo, 1989, 65.

14 Cf. Ratzinger, "Sobre la esperanza", 391, 396.

15 Cf. Joseph Ratzinger, Mi vida, 1997, Madrid, Encuentro, 2006, 174-175.

16 Para apreciar la incidencia real de estos autores obsérvese la relevancia de Schlier, citado doce veces en relación a tres de sus obras (Besinnung auf das Neue Testament, Freiburg i. B. 1964; Das Ende der Zeit, Friburgo 1971; Der Römerbrief, Freiburg i. B. 1977), frente a Käsemann citado cuatro veces en su obra An die Romer, Tübingen 1973; Koester y Rensgtorf, citados una sola vez en relación a Theologisches Wörterbuch zum Neuen Testament, Stuttgart 1933; y Gese en su obra Zur biblischen Theologie, München 1977.
} 
y Ef 4,4-6, que presenta la unidad de la esperanza cristiana en relación a la llamada única de Dios al hombre en coherencia con la unidad del cuerpo y del Espíritu. Igualmente, nuestro teólogo se remite a 1 Tes 4,13, donde Pablo habla a los cristianos de Tesalónica sobre la esperanza más allá de la muerte para que no se entristezcan como los hombres que no tienen esperanza; a 2 Cor 3,12, donde la acción del Espíritu en la nueva Alianza se hace acreedora de esperanza; a Gál 5,5, donde la fe permite la esperanza de la salvación; a Col 1,23, que vincula la esperanza contenida en el Evangelio a la perseverancia en la fe; y a la Carta de Tito 2,13 que cifra la esperanza cristiana en"la manifestación de la gloria del gran Dios y Salvador nuestro, Jesucristo". Finalmente, a estas citas, hay que sumar la exhortación de 1 Pe 3,15 a dar razón de la esperanza, referencia aquí a la necesidad de exponer la fe.

Este elenco de textos le sirve a Ratzinger para evidenciar tres ideas nucleares: 1) La esperanza como signo distintivo del cristiano frente a la desesperanza en la que viven los que desconocen a Dios; 2) La esperanza, para ser tal, debe dar plena satisfacción a los anhelos del hombre más allá de la muerte; 3) La comunicación interior entre fe y esperanza, ya sea en términos antropológicos como teológicos, porque la fe alumbra la esperanza como esta, a su vez, nutre la fe. El fundamento de estos vectores es Cristo, quien, con su muerte y resurrección, se ha revelado razón de cuanto existe y principio de su realización más allá incluso del límite que impone la muerte, tal como la esperanza requiere. La razón para la esperanza y su garante vienen así a identificarse. Hay motivos para la esperanza porque el autor mismo de la vida ha comprometido su palabra y la rubricó con la ofrenda de sí en la cruz. La esperanza deja de ser de este modo mero anhelo para ser persona: Jesucristo, respuesta personal y concreta, real y plena, a cuanto la vida desde sus entrañas reclama.

El centro cristológico de la esperanza viene amparado en Ratzinger por Jn 14,2.6, donde la afirmación “Yo soy el camino y la verdad y la vida" se comunica con las"muchas estancias" que el Señor se dispone a preparar, y Lc 23,43, donde la promesa al ladrón arrepentido une ambos sentidos. Estos textos hacen realidad para nuestro teólogo el salmo 23,1.4: "El Señor es mi pastor, nada me falta [...] Aunque camine por cañadas oscuras, nada temo, porque tu vas conmigo". ${ }^{17}$ De modo que, en Cristo, la creación entera (humanidad incluida) ve su orden intramundano abierto en trascendencia. Fruto de esta identidad entre los motivos para la esperanza y su garante, esperanza y fe se corresponden. La esperanza

17 Complementa esta idea su lectura de Jn 5,24; 11,25; 17,3, cf. RATZINGER, “Mi felicidad es estar cerca de ti", 437-439. 
conduce a la fe en Cristo del mismo modo que la fe en él causa esperanza. Ambas se comunican y se alimentan mutuamente. ${ }^{18}$

A la luz de los textos referidos del Nuevo Testamento queda claro, estima Ratzinger, que "la esperanza no es simplemente un artículo entre otros, sino directamente la definición de la existencia cristiana" ${ }^{19}$ En efecto, por la redefinición ontológica de la existencia que Cristo causa, abriéndola a su plena satisfacción, "ser cristiano significa ser alguien con esperanza, entrar en la dinámica de una esperanza auténtica" ${ }^{20}$ Esta esperanza de la que vive el cristiano, al punto de caracterizarlo, abre la realidad presente al futuro, más allá incluso del límite por antonomasia que es la muerte. Y finalmente, dado que la esperanza para el cristiano tiene su fundamento en la palabra dada por Dios al hombre en Jesucristo y en la credibilidad de la que se ha hecho acreedor al entregar su vida, la esperanza cristiana vive de la fe en él como esta se nutre de la esperanza en que cumplirá su palabra. Existe una comunicación interna entre esperanza y fe.

Sin embargo, el texto que Ratzinger desmenuza largamente y sobre el que hace caminar su exposición sobre la esperanza es la Carta a los Hebreos. En ella, el teólogo advierte la conjunción de los tres elementos nucleares antes indicados: la esperanza como signo identitario del cristiano, la satisfacción plena de la existencia más allá de la muerte, y la comunicación íntima entre fe y esperanza. El punto de unión de todo el

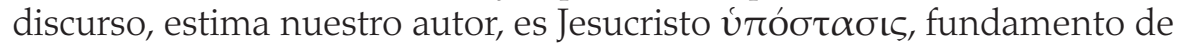
cuanto existe (cf. Heb 1,3).

Esta afirmación con la que abre la Carta a los Hebreos define consigo, según Ratzinger, lo verdadero-definitivo de lo aparente-caduco $\mathrm{y}$ ofrece al hombre en Cristo un nuevo enraizamiento vital que desde el presente lo abre al futuro. Heb 10,32-39, en su opinión, describe de modo singular esta circunstancia. Si bien"los cristianos, por causa de su

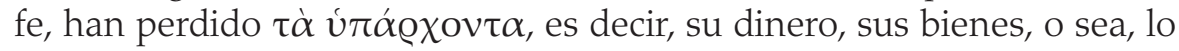
que en la vida común parece ser la" «substancia» sobre la cual se puede construir una vida. [...], en la pérdida de lo que comúnmente constituye la «substancia», el suelo de la vida, se ha puesto de manifiesto que ellos tenían una ứ $\alpha \varrho \xi ı$ mejor, una riqueza mayor y más duradera que nadie

\footnotetext{
18 "La fe y la esperanza no son separables una de la otra": RAtzinger, Mirar a Cristo, 74. Esta relación desde el punto de vista antropológico, cf. Pedro Laín EnTRalgo, Creer, esperar, amar, Barcelona, Círculo de Lectores, 1993, 168-170.

19 RATZINGER, "Sobre la esperanza", 390.

20 RATZINGER, "Sobre la esperanza", 390.
} 
puede arrebatar". ${ }^{21}$ El término út $\alpha \varrho \xi$ ı५ viene aquí leído por Ratzinger como forma de existir:" nosotros - los cristianos - tenemos otra forma de existir, vivimos sobre otro suelo del que nadie puede arrancarnos, ni siquiera la muerte" ${ }^{22}$ La redefinición de la substancia sobre la que apoyar la existencia y edificar una vida comporta así la superación de lo inmediato hacia un nivel ontológico mayor al temporal.

Lo temporal/caduco frente a lo eterno/definitivo que presenta la Carta a los Hebreos puede parecer una apropiación de la concepción platónica del mundo; pero, advierte Ratzinger, "si se sigue todo el razonamiento se verá que este esquema obedece a una dinámica de la esperanza que únicamente podía nacer del encuentro con Cristo resucitado, con la promesa que él anuncia y es" ${ }^{23}$ Esto es, la fuente de la esperanza no radica en un hipotético mundo de las ideas que nos salva de las apariencias, sino en la persona de Jesucristo, principio fundante de cuanto existe y al que está llamada la realidad entera. Así, frente a los bienes en los que el mundo deposita su confianza y cifra su esperanza, Cristo representa el verdadero bien fundante de la realidad. Por tanto, quien deposite su confianza en él no quedará defraudado en su esperanza (cf. Heb 3,14). Bajo esta clave, Ratzinger lee las Bienaventuranzas. ${ }^{24}$

Sin embargo, mientras el hombre vive bajo las condiciones de lo temporal, la contradicción entre lo visible-inmediato, con sus glorias, y lo definitivo confiado al futuro requiere por parte del cristiano una perseverancia guiada por la fe. Para Ratzinger, la palabra clave aquí es útouoví a la que exhorta la Carta a los Hebreos. "En esta palabra que se traduce habitualmente como paciencia, se funden dos aspectos, el ontológico y el espiritual: tenemos un fundamento firme, más sólido que los bienes tangibles. Con la solidez de ese fundamento guarda correspondencia la firmeza y libertad de aquel que se ha emancipado de los poderes que disponen sobre lo tangible. De modo que, mucho más que «paciencia» en el sentido corriente, esta actitud es un nuevo afirmarse en el ser". ${ }^{25}$ La esencia de esta actitud se hace aun más nítida en su contraria, "la

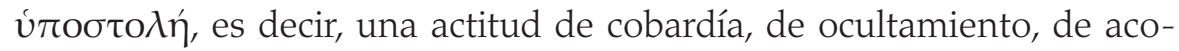
modación a cualquier precio que corresponde a la falta de fundamento

21 RATZINGER, “Sobre la esperanza”, 398. La consideración de esta idea sobre la base de 2 Cor 6,8-10 en: Ratzinger, Mirar a Cristo, 1989, 62-63.

22 RATZINGER, "Sobre la esperanza", 398.

23 RATZINGER,"Sobre la esperanza", 399.

24 Cf. Ratzinger, Mirar a Cristo, 1989, 61-69.

25 RATZINGER, “Sobre la esperanza”, 398. 
y de verdad de una vida vacía, que solo quiere salvar el propio pellejo y, justamente de este modo, se pierde (Heb 10,32-39)". ${ }^{26}$

De acuerdo a esta lógica sobre lo real y su fundamento, la Carta a

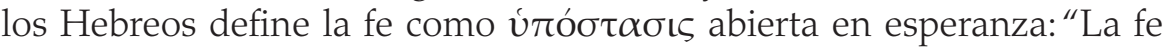
es el fundamento de lo que se espera y la prueba de lo que no se ve" (Heb 11,1). Luego, entiende Ratzinger:"Creer significa salir del juego de sombras de las cosas caducas y alcanzar el suelo firme de la realidad verdadera, la «hipóstasis», literalmente: aquello en lo que se está firme y sobre lo que es posible afirmarse. Dicho de otro modo: creer significa haber encontrado un suelo, llegar a la verdadera substancia de todas las cosas" ${ }^{27}$ Este suelo firme, que es Cristo, sobre el que asentar la existencia es lo que permite la esperanza cierta. "Con la fe, la esperanza se ha «afirmado»: el grito de expectativa que brota de nuestro ser no cae en el vacío, sino que encuentra un asidero firme que nosotros, a su vez, tenemos que sostener con firmeza". ${ }^{28}$ Esperar es, por tanto,"vivir en la verdad fundamental de nosotros mismos, vivir desde el cuerpo de Cristo y en el cuerpo de Cristo" ${ }^{29}$ De donde no es extraño, en consecuencia, que fe y esperanza entren en sinonimia según aparece en Heb 10,23, donde la confesión de la fe viene recogida como "confesión de la esperanza". Así, para Ratzinger, la fe al dirigir la existencia hacia su último y verdadero fundamento - Jesucristo - otorga esperanza porque confía la vida al único que puede satisfacerla plenamente.

Finalmente, Ratzinger también se remite a la Carta a los Romanos 8,19-26 para tocar el complejo nudo que ata la creación, hombre y cosmos, en unidad de destino. Según advierte en ese pasaje, "el tema de la esperanza se amplía aquí por necesidad intrínseca a la pregunta de la relación entre el hombre y la creación. El hombre está tan profundamente unido con la creación que no puede haber salvación alguna para

26 RAtZinger, "Sobre la esperanza”, 398-399.“Cuando los bienes se presentan de por sí como garantía de futuro surge una figura falsa de esperanza que, al final, solo puede

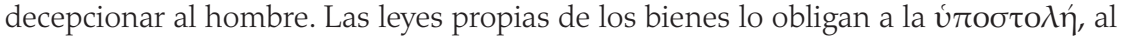
juego de las adaptaciones, por las que se quiere asegurar la simpatía de los poderes dominantes para conservar la propia «substancia». Pero quien procura asegurarse por medio de la mentira su posición, podrá salvar su estatus: $\tau \dot{\alpha} u ́ \pi \alpha ́ \varrho \chi o v \tau \alpha$; Pero el precio que paga por ello es demasiado elevado: se destruye a sí mismo y pierde su verdadero fundamento (la «hipóstasis»)": RATZINGER, "Sobre la esperanza", 399.

27 RatZinger, "Sobre la esperanza", 397. En la misma dirección, cf. IDEm, “Fe y teología”, 2000, en Idem, Convocados en el camino de la fe, Madrid, Cristiandad, 2004, 22.

28 RATZINGER, "Sobre la esperanza", 397.

29 RATZINGER, "Sobre la esperanza", 400. 
él que no sea también salvación de la creación". ${ }^{30}$ La creación respecto al hombre no es, pues, mera tramoya, sino que ella también fue llamada a la vida por Dios y como tal aguarda su plenitud. ${ }^{31}$ Forma parte de la fe cristiana de todos los tiempos, escribe nuestro teólogo, "la esperanza de que la historia llegará a un final y que, con él, la humanidad como totalidad alcanzará su plenitud y el mundo de la materia adquirirá una importancia definitiva" ${ }^{32}$ Ratzinger apunta con ello a uno de sus grandes temas: la dimensión cósmica de la salvación, que comporta de modo inmediato una responsabilidad del hombre sobre lo creado. $\mathrm{Al}$ respecto, afirma: "También la creación espera. Aquí es importante que, según el Apóstol, la esperanza de la creación no se dirige a sacudirse el yugo del hombre. Antes bien, la creación espera al hombre transfigurado, al hombre convertido en hijo de Dios. Este hombre le devolverá también su libertad, su dignidad, su belleza primera. Solo a través de él llegará ella misma a ser algo divino". ${ }^{33}$

En su lectura de Rom 8,19-26 sobre la creación expectante vinculada a la redención del hombre, Ratzinger hila la comprensión paulina sobre lo creado con la razón para la esperanza que ofrece la Carta a los Hebreos, singularmente Heb 10,32-39. Frente a la falsa esperanza del poseer que frustra al hombre y genera una actitud avasalladora sobre la creación, una vida anclada en Cristo abre al hombre a la esperanza por encima de los bienes materiales al tiempo que le ubica adecuadamente ante lo creado. La esperanza cristiana colma así al hombre y libera la creación de su afán de dominio que la esclaviza.

\section{RATZINGER EN DIÁLOGO CON ERNST BLOCH}

En su reflexión, Ratzinger no es ajeno al pensamiento contemporáneo, especialmente a la crítica marxista de la esperanza cristiana y a la alternativa intramundana que este presenta. En este diálogo, su interlocutor privilegiado es Ernst Bloch, con quien coincidió en la Universidad

30 RATZINGER, "Sobre la esperanza", 404. Compartiendo la tesis principal sobre la unidad de destino de la creación y el hombre, Ernst Bloch resuelve esta relación no en la trascendencia sino anegando al hombre en la naturaleza, vista esta como sola y pura materia, cf. Laín ENTRALGO, Creer, esperar, amar, 180.

31 Han considerado Rom 8,19-26 con similar lectura: Xavier ZubIRI, Estructura dinámica de la realidad, Madrid, Alianza Editorial, 1989; Laín EnTRALGo, Creer, esperar, amar, 150151, 155, 194-195.

32 RAtZinger, "La resurrección de Cristo y la esperanza”, 347-348. El desarrollo de esta idea en: IDEM, Escatología, 210-214.

33 RATZINGER, “Sobre la esperanza”, 404. 
de Tubinga al final de la década de los $60 .{ }^{34}$ Pese a las sustanciales diferencias con él, Ratzinger reconoce el mérito de su obra que "con su Principio Esperanza ha hecho de este tema ya olvidado la pregunta central de toda filosofía". ${ }^{35}$

Primero en Marx y luego en Bloch, Ratzinger advierte la redefinición de la noción de esperanza que ha operado el marxismo. Al reducir lo real a la sola materia, el marxismo no solo excluye cualquier consideración trascendente de la existencia, sino que cierra al completo su horizonte de posibilidades al plano material-intramundano. Toda expectativa que supere este umbral se considera alienante, singularmente la promesa de vida más allá de la muerte confiada a un Dios garante de la satisfacción plena del hombre. Tal como Bloch la concibe, la única esperanza posible viene acotada por el mundo físico, siendo la historia su escenario. La esperanza aquí es producto de la acción humana. Todo aquello que el hombre "no pueda hacer por sí mismo debe ser eliminado conscientemente de la esperanza. No deben existir expectativas que escapen a las posibilidades humanas". ${ }^{36}$ La esperanza ofrecida por el marxismo se dibuja así en torno a la mejora de las condiciones de vida con negación de los anhelos últimos del hombre. De aquí que el mundo sea descrito por Bloch como Laboratorium possibilis salutis. Así las cosas, Bloch alcanza la tesis contraria a san Pablo. Si para el Apóstol la esperanza era un bien propio de los creyentes porque solo Dios puede satisfacer los anhelos más íntimos de la existencia, más allá incluso de la muerte, para el marxismo, la esperanza es patrimonio del ateo porque asume las riendas de la historia y trabaja por trasformar este mundo sin remisiones ficticias a un Dios, ni a un paraíso. ${ }^{37}$

34 "Ernst Bloch enseñaba entonces en Tubinga y en sus lecciones denigraba a Heidegger, catalogándolo de pequeño burgués": Ratzinger, Mi vida, 163. En Tubinga, Ratzinger coincide también con Jürgen Moltmann, quien acababa de publicar su emblemática obra Teología de la esperanza por aquellos años, donde "repensaba la teología a partir de Bloch": Joseph Ratzinger, Mi vida, 163. Sin embargo, Moltmann y su Teología de la esperanza apenas inciden en la obra de Ratzinger.

35 RATZINGER, "Sobre la esperanza", 391.Vuelve a subrayar la importancia de su reflexión en: IDEM, Mirar a Cristo, 47. No obstante, por nuestra parte, apuntamos la aportación de Gabriel Marcel con su obra Homo viator: Prolégomènes à une métaphysique de l'espérance (1944) y de Pedro Laín Entralgo con su obra La espera y la esperanza (1957) en la recuperación del tema esperanza para la filosofía. Si bien Kant ya indicó que la cuestión “QQué me es dado esperar?" era una de las cuatro preguntas a responder por la filosofía, lo cierto es que la esperanza no ha tenido un peso específico en la filosofía hasta el siglo XX de la mano de los citados autores.

36 RATZINGER,"Sobre la esperanza", 394.

37 Cf. Ernst Bloch, Das Prinzip Hoffnung, Francfort, Suhrkamp, 1957, 1524. 
No obstante, admitiendo la comprensión marxista de la existencia con su única esperanza en el progreso material, Ratzinger señala agudamente cómo esta no deja de remitir el presente a un futuro donde las expectativas humanas quedan satisfechas, aunque estas hayan sido recortadas al plano material-intramundano. ${ }^{38}$ Algo así como un Reino de los Cielos en la tierra a cargo del hombre. Con lo cual, advierte nuestro autor, Marx y Bloch no proponen otra cosa en su fondo que una versión materialista intramundana del Paraíso, cuyo camino creen haber encontrado a través de la lucha de clases y la dictadura del proletariado. El hombre artífice del cielo en la tierra sin necesidad de Dios. ${ }^{39}$ A esta tarea deben entregarse - incluso sacrificarse- las generaciones presentes en aras de un mundo futuro ideal que justifica todas las acciones..$^{40} \mathrm{El}$ propio Bloch confiesa que el marxismo, en esencia, es "sueño hacia delante". ${ }^{41}$ Llegados a este punto, indica Ratzinger, parece que la misma crítica que el marxismo lanza al cristianismo se vuelve contra él; pues, si el marxismo recrimina al cristianismo el adormecimiento del hombre bajo la promesa de la satisfacción de sus anhelos en el "más allá" Reino de los Cielos, la propuesta marxista somete al hombre a sus dictados bajo la promesa de un mundo ideal aún no verificado en la historia. ${ }^{42}$

Si bien, a tenor de lo visto, la esperanza marxista está internamente movida por la consecución de un Paraíso (aunque este sea intramundano) donde los anhelos humanos vengan satisfechos, entre la propuesta marxista y la cristiana hay notables diferencias; y no solo de umbral de realización como aprecia Laín Entralgo. ${ }^{43}$ Ellas divergen radicalmente entre sí en sus expectativas, en su horizonte de realización y en el garante de las mismas. El cristianismo, a diferencia del marxismo, reconoce en el hombre aquellos anhelos que van más allá del progreso material y les ofrece una satisfacción. Pese a las críticas que puedan hacerse (algunas no sin razón), la esperanza cristiana no se inhibe del aquí y ahora personal y colectivo del hombre (cf. GS 39) ${ }_{i}^{44}$ sin embargo su realización trasciende el orden intramundano. Por último, sin excluir el papel del

38 Cf. Ratzinger, Mirar a Cristo, 47.

39 Cf. RAtZinger, “Sobre la esperanza”, 394-395.

40 "La dinámica del progreso hace que todo sea justo": Ratzinger, Mirar a Cristo, 53.

41 "Träume nach vorwärts": BLoch, Das Prinzip Hoffnung, 1616.

42 "Este mundo, para cuya construcción se utilizaría el presente, nunca nos afecta a nosotros mismos; únicamente existe para una futura generación todavía desconocida, que nunca llega": RATZINGER, "Mi felicidad es estar cerca de ti”, 440.

43 Cf. Laín Entralgo, Creer, esperar, amar, 181.

44 Que la esperanza de inmortalidad desvalorice este mundo es para Ratzinger una visión errónea ya que"la esperanza en el más allá significa para el cristiano responsabilidad ante Dios en este mundo": RATZINGER, “La resurrección de Cristo y la esperanza”, 348. 
hombre en la consecución de sus anhelos, la esperanza cristiana tiene a Dios por garante último de la plena satisfacción del ser humano. En cambio, la propuesta marxista, fruto de su lectura materialista, reduce toda expectativa humana al progreso material, amputando con ello los anhelos últimos del hombre, cifra su horizonte en logros intramundanos y vive confiada a las solas manos del hombre (bajo la tutela del partido, claro). Respecto de la esperanza cristiana, estima Ratzinger, el marxismo hace suya la promesa de satisfacción futura que muta en utopía social y el fervor en su consecución bajo forma de optimismo ideológico, pero la rompe en su núcleo al excluir a Dios de ella. ${ }^{45}$ El resultado es perverso: la esperanza reducida a construcción social, cuyo proceso gestiona el partido político como instancia inapelable que ocupa el lugar de Dios dentro de la nueva religión atea del progreso histórico. ${ }^{46}$

No obstante, la clave argumental de Ratzinger en su crítica a Bloch radica en la esencial distinción entre las nociones esperar y hacer; esta última, base de la redefinición de la esperanza enunciada por Bloch. Para nuestro teólogo, "hacer y esperar se encuentran en dos planos totalmente distintos. El hombre necesita la esperanza justamente porque lo producido y lo susceptible de ser producido no le bastan" ${ }^{47}$ La esperanza se sitúa más allá de cuanto el hombre puede fabricar con sus manos o conquistar con su esfuerzo. Ella se define sobre los anhelos más íntimos de la persona, trascendiendo lo esperable como consecución probable, ya sea a nivel biológico, histórico o de cualquier otro tipo. ${ }^{48}$ "Desde su temporalidad y su finitud, la realidad personal de cada hombre y la historia universal de la humanidad postulan consciente o inconscientemente la eternidad y la infinitud". ${ }^{49}$ Por contra, la esperanza propuesta por Bloch se define a partir de los bienes previsibles a manos del hombre. De donde, en consecuencia," no hay nada que esperar; lo que esperamos debemos hacerlo nosotros mismos y no se nos da nada más allá de nuestro

45 De la suplantación de la esperanza por el optimismo ideológico, cf. RATZINGER, Mirar a Cristo, 50-54; IDEM, "Mi felicidad es estar cerca de ti", 440.

46 "Queda la esperanza, pero el puesto de Dios es reemplazado por el partido y, por tanto, el totalitarismo de un culto ateo que está dispuesto a sacrificar toda humanidad a su falso dios": Ratzinger, Mi vida, 163-164. Idea similar en: Idem, Mirar a Cristo, 52.

47 Ratzinger, "Sobre la esperanza", 395.

48 "La esperanza es, por esencia, de índole personal: si bien apunta a algo que va mucho más allá de la propia persona — una nueva tierra, el paraíso—, apunta hacia allí porque la persona lo necesita": RATZINGER, "Sobre la esperanza", 395.

49 Laín Entralgo, Creer, esperar, amar, 172. 
propio poder" ${ }^{50}$ Luego, tal como ve José Ferrater, Bloch presenta una esperanza puramente psicológica. ${ }^{51}$

\section{LA CUESTIÓN ESPERANZA EN SU RADICALIDAD}

Más allá de la esperanza como posibilidad humanamente probable, Ratzinger se interesa por la llamada esperanza fundamental, aquella que apunta a la satisfacción plena de la existencia más allá de todo límite, tipología que adopta de Herbert Plügge. ${ }^{52}$ La esperanza aquí no se define a partir de lo humanamente factible, sino sobre el reclamo de la existencia para verse satisfecha. En este cambio de parámetro radica la distinción esencial entre ambas y, en consecuencia, la tematización que se haga de la esperanza.

Siendo la espera de lo posible, en términos de probabilidad, un elemento de la razón proyectiva, la espera del bien previsible no es, sin más, la esperanza para Joseph Ratzinger. Si la consecución de unas condiciones óptimas de vida colmase los anhelos más íntimos del hombre, la cuestión de la esperanza estaría resuelta; pero no es así. Por contra, indica nuestro teólogo,"la verdadera problemática antropológica de la esperanza consiste en que el hombre necesita algo que va más allá de todo lo que está en su poder".$^{53}$ En efecto, sobre cualquier meta alcanzada, como escribe Pedro Laín Entralgo, "el hombre espera siempre más". ${ }^{54}$ Aquello que lo llenó de esperanza y propulsó su esfuerzo queda vencido en el instante mismo del bien logrado. El paso dado hacia delante le satisface, pero no lo colma. Tras el umbral conquistado, su mirada busca ya un nuevo horizonte de realización hacia el cual, por lo demás, se siente íntimamente impelido: "para nuestra mente, lo cierto será siempre penúltimo y lo último siempre será incierto" ${ }^{55}$ El existente humano se dibuja así en protensión sobre lo dado,

50 RATZINGER, Mirar a Cristo, 53-54.

51 Cf. José Ferrater Mora, “Esperanza”, en IDEm, Diccionario de filosofía, vol. II. Barcelona, Círculo de lectores, 1991, 1011.

52 Cf. Herbert PlügGe, Wohlbefinden und Missbefinden, Tübingen, Max Niemeyer Verlag, 1962. Junto a este autor, Ratzinger sigue la obra de Josef PIEPER (Hoffnung und Geschichte, München, Kösel Verlag, 1967), cuya noción básica de esperanza con su dinamismo y elementos antropológicos comprometidos en ella adopta, según reconoce abiertamente en el prólogo de su obra Mirar a Cristo. Allí confiesa que se ha servido de la obra de Pieper "como si fuera un libro de texto [...] Mi aportación personal ha sido la de ampliar la exposición filosófica de Pieper sobre el plano teológico y espiritual": Ratzinger, Mirar a Cristo, 7.

53 RATZINGER, "Sobre la esperanza", 395.

54 Laín EnTRALGO, Creer, esperar, amar, 158.

55 Laín EntRalgo, Creer, esperar, amar, 160. 
siempre hacia más. ${ }^{56}$ Esta hambre de ser en el existente humano revela en sí la clave de bóveda de la esperanza: el ser busca desde sus entrañas afirmarse sobre cuanto comporte frustración ${ }^{57} \mathrm{y}$, en último término, sobre la nada. ${ }^{58}$ Quiere ser, crecer en el ser, alcanzar plenitud de ser.

Si bien lo esperable forma parte de la esperanza, el bien humanamente previsible no colma su campo. La esperanza se"basa ante todo en una radical necesidad del ser humano: el hombre espera siempre más de lo que una presencia cualquiera puede darle. Cuanto más persigue ese anhelo, tanto más se da cuenta de que este rompe absolutamente los límites de lo empírico. Lo imposible es para él lo necesario. Pero esperanza significa la certidumbre confiada en que ese deseo encontrará respuesta" ${ }^{59}$ En efecto, tal como aprecia Laín Entralgo, lo genuino de la esperanza es que"trasciende a todos los posibles proyectos y ocultamente les acompaña, tiene como metas el seguir viviendo, el seguir siendo uno mismo y el ser más sin límite; en definitiva, un estado de la realidad personal en el que total y definitivamente —más allá, por supuesto, de la muerte del esperante- logren entera satisfacción todas las aspiraciones de la naturaleza humana". ${ }^{60}$ Desde sus entrañas, la esperanza humana muestra así con su deseo de satisfacción plena, más allá de cualquier conquista previsible a manos del hombre, su carácter ilimitado que ubica al hombre ante un horizonte abierto. Así, concluye Laín Entralgo: "No parece ilícito afirmar que la vida humana postula el siempre desde dentro de sí misma, que existe y opera en el ámbito del siempre" ${ }^{61}$

En su radicalidad, como satisfacción plena de los anhelos últimos del ser, Ratzinger entiende que la esperanza coloca al hombre ante sí mismo: si el hombre, al apetecer lo imposible, es un error aberrante de la naturaleza y la esperanza que vive un absurdo o, por el contrario, semejante anhelo en sus entrañas revela consigo la verdad última del hombre que, más allá de la naturaleza biológica dada, se abre en trascendencia. ${ }^{62}$ La pregunta por la esperanza se torna así cuestión esencialmente antropológica ya que no es posible dar respuesta a qué cosa sea la esperanza sin una comprensión

\footnotetext{
56 "En todo momento vive el hombre sabiendo que puede ser más de lo que entonces es": Laín ENTRALGo, Creer, esperar, amar, 157.

57 "La esperanza es rebelión contra el mal, sueño de justicia y felicidad": Vicente Ramos Centeno, "Esperanza”, en Mariano Moreno Villa (ed.), Diccionario de pensamiento contemporáneo, Madrid, San Pablo, 1997, 420.

58 "Tenemos miedo a la muerte ante todo porque tenemos miedo de la nada": RATZINGER, "Lugares de esperanza", 646.

59 RATZINGER, "Sobre la esperanza”, 396.

60 Laín ENTRALGO, Creer, esperar, amar, 181.

61 Laín ENTRALGo, Creer, esperar, amar, 181.

62 Cf. RatZinger, “Sobre la esperanza”, 395; IDEM,“Lugares de esperanza”, 647.
} 
del hombre. Esto es, si el hombre es mera naturaleza sin trascendencia o la trascendencia forma parte de su naturaleza. Según se entienda al hombre tendremos una comprensión de la esperanza y a la inversa. Las preguntas por el ser del hombre y qué cosa sea la esperanza se implican mutuamente. ${ }^{63}$

Si seguimos los postulados de Ernst Bloch, la esperanza debe ceñirse a las posibilidades fácticas de su realización por el hombre y, en consecuencia, lo humanamente posible delimita la esperanza. El hombre con sus límites se convierte en medida de la esperanza. Sin embargo, para Joseph Ratzinger, semejante composición rompe de raíz la noción esperanza, pues ella se define no a partir de lo humanamente posible, sino desde lo más hondo del existente humano que insaciablemente busca plena satisfacción en el orden del ser; algo que solo a partir de sí mismo se antoja imposible. ${ }^{64}$ Aun cuando el hombre viva en condiciones razonablemente óptimas desde un punto de vista material (vivienda, sanidad, educación...), ninguna garantía social puede saciar su espontánea sed de verdad, justicia, libertad, igualdad, bondad, belleza... y, al final, de ser:"el hambre de lo infinito siempre le acompaña". ${ }^{65}$ De hecho, las mejoras en las condiciones de vida beben y tienen su motor en el horizonte de realización que dichas nociones afirman.

En cambio, para Ratzinger, la noción esperanza se define a partir de cuanto el existente humano reclama desde sus entrañas como adecuado a su ser para verse colmado. Aquí, lo posible a manos del hombre no configura el centro de la noción, ni es factor limitante de la misma. Por contra, a partir del ansia de satisfacción plena que palpita en el corazón del ser humano, tal noción de esperanza reclama para el hombre incluso lo imposible. "Si la experiencia de carencia, la paradoja del deseo, tiene que conducir de por sí al ser humano a desesperación de sí mismo y de su razón de ser, esa certidumbre será, a la inversa, una secreta alegría más allá de todas las alegrías y sufrimientos empíricos, de modo que el hombre es rico justamente por su carencia, y desde ella recibe (a través de la esperanza) una felicidad que, sin ese extenderse en la esperanza,

63 José Ortega y Gasset vio claramente esta relación, al punto de considerar la esperanza nota definitoria del hombre:" ¿Qué es en el hombre la esperanza? ¿Puede el hombre vivir sin ella? [...] ¿Es posible un humano vivir que no sea un esperar? ¿No es la función primaria y más esencial de la vida la expectativa, y su más visceral órgano la esperanza?": José Ortega y GASSET, El hombre y la gente, en IDEM, Obras Completas, vol.VII, Madrid, Revista de Occidente, 1961, 111. Tal implicación antropológica de la esperanza significa que "la esperanza no es solo una determinación de los afectos de espera, sino que pertenece a la condición ontológica del hombre": RAmOS CENTENO, "Esperanza", 419.

64 Cf. RatZingeR, “Lugares de esperanza”, 647.

65 Ratzinger, Mirar a Cristo, 76. 
no podría experimentar" ${ }^{66}$ Lo humanamente factible deja de ser medida de la esperanza para ser ahora esta la que se convierte en medida del hombre, ensanchando sus límites y desvelando su misterio en trascendencia. La existencia del hombre encuentra así, vía esperanza, una suerte de apoyo a la hora de lograr una respuesta esclarecedora sobre sí. ${ }^{67}$ Esta noción de esperanza, por definición, presupone una consideración abierta del hombre en medio de un orden que se antoja cerrado. Dicho de modo práctico:"Solo quien puede reconocer en la muerte una esperanza es capaz de vivir también en la vida a partir de la esperanza". ${ }^{68}$

\section{SUJETO Y OBJETO DE LA ESPERANZA}

Quizás lo más sugestivo de la reflexión que Joseph Ratzinger despliega sobre la esperanza sea cuando se pregunta: ¿Quién espera? y ¿qué esperan los que esperan? ${ }^{69}$ Esto es, cuál es el sujeto y el objeto de la esperanza.

Tomando como referencia al apóstol Pablo en la Carta a los Romanos (cf. Rom 8,19-26), Ratzinger concibe la creación en espera porque "la promesa no deja de lado la naturaleza, sino todo lo contrario". ${ }^{70}$ Sugerir que plantas y animales esperan, que el planeta o el cosmos espera, resulta cuando menos extraño a la visión hipersicologizada — hoy imperante- de la esperanza. El pensamiento paulino sobre la creación esperante se entiende así dentro de una lógica teológica, a la cual se reduce el valor de su afirmación. A lo sumo se ve como un escarceo místico del apóstol. Pero la creación, sujeto de esperanza, ¿es mera poética? ¿Tiene sentido solo dentro de una lógica teológica? Para Ratzinger no, al igual que para Xavier Zubiri o Pedro Laín Entralgo.

Desde un plano puramente metafísico, observa Zubiri, la dimensión hacia pertenece constitutivamente a la realidad en todas sus formas, que lanza al existente hacia delante. ${ }^{71}$ Constatación similar hace Laín Entralgo, quien observa una protensión de todo cuanto existe a ser, mantenerse en el ser (ser siempre) y crecer en el ser (ser más). ${ }^{72}$ Para ambos, la misma materia en su constitución estructural evidencia protensión: la

66 RATZINGER, "Sobre la esperanza", 396.

67 CF. Laín Entralgo, Creer, esperar, amar, 148.

68 RATZINGER, "Lugares de esperanza”, 647.

69 Cf. Ratzinger, “Sobre la esperanza”, 391, 396.

70 RatZinger, Mirar a Cristo, 70.

71 Cf. ZuBIRI, Estructura dinámica de la realidad.

72 "Desde que aparecieron las partículas elementales en los primerísimos instantes de la génesis del cosmos, el movimiento de los entes materiales hacia el futuro, la evolución de la materia, ha sido realidad constante": LAín EnTRALGO, Creer, esperar, amar, 149. 
esencial tendencia a avanzar respecto del ser dado. Esta propiedad causó la proestructuración de partículas elementales en complejas, la molecularización, la vitalización, la vegetalización, animalización y finalmente la hominización, donde la estructural tendencia hacia de la realidad conoce la capacidad de la realidad sobre sí. En este punto, aparece propiamente la esperanza sobre todos los niveles anteriores que solo conocen la espera. ${ }^{73}$ Según vemos, la reflexión metafísica de Zubiri o el proceso de la materia descrito por Laín Entralgo no queda lejos de la comprensión paulina de una creación expectante reivindicada por Ratzinger.

No obstante, la creación en su espera está sujeta al hombre. El destino de ambos se entrelaza. Si la creación entera es donación de ser, el hombre inserto en ella tiene, sin embargo, capacidad para abrirse o cerrarse, libertad para acoger o rechazar. Este hecho carga al hombre con una responsabilidad sobre sí y sobre la realidad con la cual comparte ser, pues le atañe que lo creado cumpla su ser-don. Con otras palabras, el modo en el cual el hombre se dispone e interactúa con la realidad marca el proceso de ser. Así, un hombre clausurado sobre sí frustra lo creado porque interactúa con ella desde la codicia, rompiendo internamente su ser-don. La creación viene entonces"sometida a la nulidad, es decir, ella misma está enredada en la mentira del hombre sobre el ser" ${ }^{74}$ Pese a este sometimiento frustrante en el cual se ve lo creado, ella suspira y espera al hombre verdadero que, instalado en el ser y no en el poseer, la conduzca a la realización de sí.

Para Ratzinger, tipo de este hombre nuevo es san Francisco de Asís. Frente al monto de expectativas materiales a las que el hombre puede confiar su esperanza de futuro, Francisco presenta una felicidad cumplida en este mundo libre de todo afán. Visto a ras de suelo, Francisco era un joven derrotado en su honor de caballero que, además, había perdido la salud en aquella empresa. Aun más, renuncia al amparo familiar, estatus social y bienes terrenos en pos de una vida de total desprendimiento. Mediante este paso —entiende Ratzinger- Francisco "se libera de la dictadura del tener, de aquel error fundamental del afán de poseer que ve la verdadera «sustancia» de la vida en la riqueza". ${ }^{75} \mathrm{Al}$ volar más allá de toda expectativa mundana de bienes o reconocimiento social, Francisco "hizo visible detrás de las falsas esperanzas la auténtica, verdadera esperanza que nadie puede confiscar y nadie puede destruir".${ }^{76}$ En efecto, apostilla Ratzinger, "cuando todas las esperanzas se han desvanecido,

\footnotetext{
73 Exposición detallada del proceso en: Laín EnTRALGo, Creer, esperar, amar, 150-162.

74 RATZINGER, "Sobre la esperanza", 404.

75 RATZINGER, "Sobre la esperanza", 399.

76 RATZINGER, "Sobre la esperanza", 399.
} 
cuando se han atravesado todas las decepciones, solo entonces destella la «esperanza fundamental» en su grandeza". ${ }^{77} \mathrm{El}$ tener como fundamento del ser es superado por un elemento nuevo y liberador: Jesucristo, quien colma el corazón humano y desvela la falsa esperanza del acaparar o del aparentar. ${ }^{78}$

Además de la espera ontológica junto al cosmos, Joseph Ratzinger concibe al hombre existencialmente abierto al otro. Siguiendo a Platón, encontrar este alguien constituye para nuestro teólogo la primera de las esperanzas. ${ }^{79}$ La espera del hombre se torna aquí propiamente esperanza porque este anhelo vital acontece en el orden de la libertad, no en el de la necesidad. De esta esperanza primera brotan, en su opinión, todas las demás y a ella están de algún modo referidas. La experiencia de correspondencia que llena la existencia constituye así para Ratzinger la vivencia originaria que pauta la esperanza:"las cosas particulares se convierten en esperanzas por el hecho de que, por decirlo así, llevan en sí el color vivencial del amor" ${ }^{80}$

Esta experiencia de correspondencia en el amor que sacia la vida reclama por sí misma trascender toda contingencia. Pide lo absoluto y el siempre que el amor por definición enuncia. ${ }^{81}$ De aquí, entiende Ratzinger, la frustración que el hombre siente ante su pérdida y la rebeldía ante la muerte:"no podemos creer que tantas cosas grandes y llenas de sentido que han crecido a lo largo de una vida deban precipitarse de repente en la nada. Nos resistimos a ella porque el amor reclama eternidad y porque no podemos aceptar la destrucción del amor que la muerte trae consigo" ${ }^{82}$ La esperanza de un paraíso, donde lo dado en el amor pueda realizarse plenamente, aparece aquí como necesidad interna del amor. Ahora bien, considera Ratzinger, la vida más allá del límite que impone la muerte al ser humano implica un amor absoluto por parte de un otro eterno: "la vida eterna solo puede tener sentido en una totalidad completamente nueva del amor que trascienda toda temporalidad". ${ }^{83}$

77 RAtZinger, "Sobre la esperanza”, 401.

78 Cf. RatzingeR, "Sobre la esperanza", 403-404.

79 "la esperanza que está por encima de las esperanzas es la certidumbre confiada de que se recibirá el don del amor": RATZINGER, "Sobre la esperanza", 393.

80 RATZINGER, "Sobre la esperanza", 393.

81 "El hombre necesita la respuesta de amor humano, pero esa respuesta pregunta, a su vez, por lo absoluto, por lo infinito": RATZINGer, "Sobre la esperanza", 394. La exposición completa de esta afirmación en: IDEM, "Sobre la esperanza", 396-397; IDEM, Mirar a Cristo, 73-74.

82 RATZINGER, “Lugares de esperanza”, 646.

83 RATZINGER, "Lugares de esperanza", 647; "no podemos prescindir de la esperanza del «paraíso», la necesidad del mismo. Pero tal necesidad es desesperación si no existe 
Esto es, la existencia de un Dios amor. Solo"si existe Dios y si ese Dios ha querido y quiere a los hombres, queda claro que su amor puede lo que el nuestro en vano pretende: conservar en vida al ser amado más allá de la muerte" .84

Como vemos, que el amor pueda cumplirse —realización de la primera y fundamental esperanza - ata dentro de sí dos cuestiones que se abrazan: vencer el límite de la muerte y un otro eterno amor absoluto. Esta comunicación interna entre amor y esperanza que requiere para su realización un tú trascendente es la base antropológica sobre la que Ratzinger ancla la vertiente teológica de la esperanza. ${ }^{85}$ Sin Dios no hay esperanza. Solo queda presunción (la esperanza en manos del hombre) o desesperanza (no hay nada que esperar, la vida es absurda). ${ }^{86}$

Si la esperanza suscita confianza ante la vida, su ausencia trae consigo un repliegue vital que puede llegar incluso a la deserción de la vida. ${ }^{87}$ La falta de bienes necesarios, pero sobre todo la decepción interior al no sentirse amado, pueden oscurecer la disposición del hombre sobre el futuro. El temor que estas vivencias infunden sobre el ánimo enuncia "el verdadero miedo, el miedo de que la propia vida pudiese malograrse en cuanto tal, de que, de ese modo, fuese a volverse tan gris y tan difícil que ya no pueda vivirse más" ${ }^{88}$ Los temores suscitados por las más diversas incertidumbres dejan paso aquí al temor radical que cierra a la persona sobre sí en negación de la vida. La angustia de todas las angustias, escribe Ratzinger, "es el miedo a no ser amados, a perder el amor, la desesperación es la convicción de haber perdido para siempre todo amor, el horror de la total soledad". ${ }^{89}$ El ser ya no se percibe como algo

certeza alguna sobre Dios y sobre una promesa divina correspondiente": IDEM, "Sobre la esperanza", 395.

84 RATZINGER, “Lugares de esperanza”, 648." «Resurrección de la carne» significa que es Dios quien da al hombre la inmortalidad: significa que el hombre puede estar seguro de que hay una vida después de la muerte porque Dios mismo, que es eterno, lo conoce, lo ama y, por decirlo así, le da, con ello, sustento en su amor": IDEM, "La resurrección de Cristo y la esperanza", 347. La exposición sistemática de la vida más allá de la muerte, inmortalidad del alma y resurrección, en: IDEM, Escatología, 96-146.

85 "Si, por un lado, esperanza y amor y, por el otro, Dios y amor son inseparables, entonces estaría claro que también la esperanza y Dios forman una unidad: que, en última instancia, sin esperanza está aquel que "vive sin Dios en el mundo»": RATZINGER, "Sobre la esperanza”, 393.

86 Cf. Ratzinger, “Lugares de esperanza”, 646.

87 Cf. RAtZinger, "Sobre la esperanza", 392. De las actitudes parejas a la desesperanza: acidia, indolencia, pusilanimidad, rencor... cf. IDEM, Mirar a Cristo, 75-84.

88 RATZINGER, "Sobre la esperanza", 392.

89 RATZINGER, "Sobre la esperanza", 392. 
bueno.90"Aquí ya no hay propiamente miedo, en el cual se esconde siempre todavía un aspecto de posible esperanza, sino la pura resignación, la desesperación como duda del ser mismo" ${ }^{91}$ Más que una actitud, la desesperanza se hace juicio global sobre la existencia: "la vida misma no es buena; lo único que cabe es sublevarse contra todo aquello que tiene responsabilidad en la desgracia de tener que vivir. La destrucción es lo único bueno que puede suceder" ${ }^{\prime 2}$

\section{LA ESPERANZA BAJO EL TIEMPO, MEMORIA Y PROFECÍA}

Joseph Ratzinger, con gran originalidad, aborda la implicación mutua entre esperanza y tiempo en varias intervenciones, aunque sin una presentación sistemática. La esperanza conjuga dentro de sí el pasado con el presente hacia el futuro. A modo de caja de resonancia, en cada presente, la esperanza trae a la memoria acontecimientos del pasado sobre los que se apoya y despliega su mirada hacia el futuro.

Para Ratzinger, "memoria y esperanza forman una unidad indisoluble".$^{93}$ La memoria afecta la esperanza y opera sobre ella a través de las experiencias pasadas que, a modo de eco vital, disponen al individuo ante el presente más o menos positivamente. Así, la memoria del bien vivido suscita esperanza y fortalece interiormente a la persona en su presente de cara al futuro. Por contra, cuando no hay nada bueno que recordar, nada se espera. Así, para nuestro teólogo,"solo quien puede recordar puede también esperar: quien nunca ha experimentado el bien y la bondad, los desconoce".$^{94}$ De donde la clave de la esperanza de presente está en cierto modo en la memoria de las experiencias positivas del pasado:"solo cuando se logra despertar en la persona desesperada el recuerdo de una experiencia del bien, esa persona se ve nuevamente en

90 "El ser no es bueno, no lo es cuando no se lo ha experimentado nunca como un sí, como ser aceptado, cuando no se ha dado la experiencia de ser amado. Esto significa que el miedo que está detrás de los miedos es el miedo a la pérdida total del amor, el miedo a una existencia en que los pequeños sinsabores de la vida cotidiana se hayan convertido en todo, en algo contra lo cual nada grande y salvador hace contrapeso. En tal sentido, los pequeños miedos, si se convierten en la única expectativa de futuro, pueden pasar a ser el gran miedo: el miedo a una vida que ya no pueda soportarse porque ya no habita en ella esperanza alguna. En este caso, la muerte se torna en la única esperanza que, sin embargo, es el fin de toda esperanza": Ratzinger, "Sobre la esperanza", 392-393.

91 RATZINGER, "Sobre la esperanza", 392.

92 RATZINGER, "Sobre la esperanza", 392.

93 Ratzinger, Mirar a Cristo, 73.

94 RATZINGER, “Una memoria que suscita esperanza”, 20. 
condiciones de creer en el bien, aprende a esperar de nuevo, se le abre un camino de salida de la desesperación" ${ }^{.95}$

Al tiempo que la esperanza activada por la memoria ilumina el presente, ella adentra positivamente a la persona en su futuro, pues permite trascender la limitación actual en virtud de lo venidero. ${ }^{96}$ La forma cristiana de este trascender es para Ratzinger la profecía. Ella nada tiene que ver con la adivinación, sino que es lectura del presente desde la palabra de Dios, lo cual comporta la crítica teológica del presente en la vigencia de las promesas divinas que impide la clausura del presente sobre sí. ${ }^{97} \mathrm{La}$ esperanza se presenta así como"la capacidad de ver la realidad preñada de futuro".$^{98}$ Por el contrario, la desesperanza describe justamente"la vacía nihilidad de lo por venir" ${ }^{99}$ La esperanza se perfila de este modo sobre el futuro:"el hombre espera del futuro una satisfacción, una felicidad que todavía no tiene. En tal sentido, la esperanza se basa en la temporalidad, que implica que el hombre no posee nunca su ser por entero" ${ }^{100}$ Aguarda siempre más: ser en plenitud.

Conforme a esta interacción entre memoria y esperanza, Joseph Ratzinger presenta el año litúrgico como memoria ecclesiae que cíclicamente trae ante el cristiano las acciones de Dios en favor de su pueblo a fin de mantener viva su esperanza. Dentro de esta composición, el Adviento "designa justamente la conexión entre memoria y esperanza que el hombre necesita. El Adviento quiere despertar en nosotros el recuerdo propio y el más hondo del corazón: el recuerdo del Dios que se hizo niño. Ese recuerdo sana, ese recuerdo es esperanza" ${ }^{101}$ Sin embargo, el recuerdo del acontecimiento pasado que recoge el Adviento no lo define al completo, es solo una parte. Tal como el mismo ad venire expresa, este tiempo litúrgico con su exclamación Maranatha dispone al cristiano hacia el que viene, Jesucristo. ${ }^{102}$ Pasado y futuro se abrazan aquí, en el presente litúrgico, para alentar la esperanza que nace de la fe. El cristianismo, asumiendo por tanto el tiempo, no se define sin embargo a partir de un acontecimiento pasado o una confianza ingenua de futuro, sino a partir de una persona Jesucristo, el Señor, quien ya vino y

95 RATZINGER, “Una memoria que suscita esperanza”, 20.

96 Cf. Ratzinger, "Sobre la esperanza", 396.

97 Cf. Ratzinger, “El problema de la profecía cristiana”, 450.

98 Ramos Centeno, “Esperanza”, 420.

99 Laín ENTRALGo, Creer, esperar, amar, 148.

100 RATZINGER, "Sobre la esperanza”, 391.

101 RATZINGER, "Una memoria que suscita esperanza”, 21.

102 Cf. Ratzinger, Escatología, 14-16. 
volverá. ${ }^{103}$ Por este motivo, concluye Ratzinger, "el cristianismo siempre lleva consigo una estructura de esperanza". ${ }^{104}$

\section{CONCLUSIÓN}

Como en otras tantas cuestiones, la consideración de la esperanza que ofrece Joseph Ratzinger entrelaza el discurso teológico con el antropológico. De modo que la comprensión creyente de la esperanza no corre en paralelo a cuanto la esperanza en su verdad demanda, sino que se corresponden, la desvela en su grandeza y, en última instancia, muestra su cumplimiento en Jesucristo. La esperanza en su exigencia de verdad es lo que la fe reconoce y viceversa. Esta visión concordante de planos, tan característica del pensamiento ratzingeriano, descansa sobre otro de los rasgos de nuestro autor: la búsqueda de verdad de la cosa misma.

Esta disposición personal marca el tratamiento de los textos bíblicos aducidos, que no se cierran sobre sí mismos, sino que ellos, en su afirmación teológica, recogen la verdad de la esperanza también en términos antropológicos. A partir de aquí, el diálogo que Ratzinger establece con los más diversos autores aparece siempre fluido. La exigencia de verdad en el tratamiento de las cuestiones evita el enquistamiento apologético, desvelando puntos de luz y carencias de algunas propuestas, v.gr. Bloch, y manifestando su correlación con cuanto la fe recoge.

De modo sintético, el estudio que ahora cerramos sobre la esperanza en el pensamiento de Joseph Ratzinger deja la cuestión en los siguientes términos:

1. Todo cuanto existe busca afirmarse en el ser, ser más, ser pleno, ser siempre. Esta protensión de todo existente dibuja lo creado en espera.

2. La disposición constitutiva hacia de todo existente se hace esperanza en el hombre desde el momento que este tiene capacidad para cerrarse o abrirse, acoger o rechazar.

3. La espera de lo creado está internamente conectada con el hombre, pues forma parte de la creación, a quien requiere para su realización.

4. La esperanza por sí misma, en su radicalidad, afirma el anhelo de serpleno inscrito en el corazón humano que se impone a cualquier límite, incluso a la negación biológica que marca la muerte.

5. La verdad de la esperanza está así en relación con la verdad misma del hombre, de modo que ella desvela su misterio trascendente más allá de todo argumento intramundano, por rotundo que sea.

\footnotetext{
103 Cf. RatZinger, “El problema de la profecía cristiana”, 449.

104 RATZINGER, “El problema de la profecía cristiana”, 451.
} 
6. Dado que la plenitud en el hombre es el amor, entregarse y ser acogido, encontrar al otro en mutua entrega es la primera esperanza y a ella se remiten de un modo u otro todas las demás esperanzas. Sin amor, no hay esperanza.

7. El amor en la esperanza afirma lo absoluto y reclama lo eterno en lo concreto de su misma experiencia, abriendo consigo dos cuestiones sucesivas pero entrelazadas: la vida más allá de la muerte y la existencia de Dios.

8. Solo un Dios amor responde adecuadamente a cuanto la experiencia del amor humano demanda y, por tanto, realiza la esperanza en el hombre.

A vuelta de su reflexión, un último pensamiento. Tal como Ratzinger aprecia, la ontología por sí dirige al hombre en su esperanza hacia Dios, remite al diálogo con él. ${ }^{105}$ La oración aparece así como esperanza en acto. "Quien reza espera en una bondad y en un poder que van más allá de sus propias posibilidades. La oración es esperanza en acto" ${ }^{106}$ Frente a quien vive entregado a la desesperación o a quien lo confía todo a sí mismo, "el orante es alguien que tiene esperanza". ${ }^{107}$ De modo singular, recuerda Ratzinger a partir del Catecismo Romano, ${ }^{108}$ el padrenuestro es la oración de la esperanza porque recoge las necesidades básicas del hombre, las ordena y las confía a Dios, origen de todo bien, a quien invoca como Padre. ${ }^{109}$

105 Cf. Ratzinger, “Sobre la esperanza”, 398.

106 RATZINGER, Mirar a Cristo, 71-72.

107 RatZInger, "Sobre la esperanza”, 405-406. Exposición similar en: IDEM, Mirar a Cristo, 72.

108 Cf. Catecismo Romano, Proemio XII; Tomas de Aquino, Suma Teológica II-II, q17, a.

109 "el Padrenuestro tiene que ver con la esperanza en virtud de su contenido. El Padrenuestro responde en su segunda parte a los miedos cotidianos del hombre y lo alienta a transformarlos en esperanza a través de la petición. Se trata del sustento cotidiano; se trata del temor ante el mal que nos amenaza de múltiples maneras; se trata de la paz con el prójimo; se trata de la paz con Dios y de la liberación del verdadero mal: la caída en la incredulidad, la desesperanza. Así, la pregunta por las esperanzas remite de por sí a la esperanza misma, a nuestro anhelo del paraíso, del Reino de Dios, con el que se inicia la oración": RATZINGER, "Sobre la esperanza", 405406. Exposición similar en: IDEM, Mirar a Cristo, 72. 